\title{
Representación mediática de la inadecuación de la víctima. Estrategia legitimadora de nuevas violencias ${ }^{1}$
}

\section{Media representation of the victim's inadequacy. Strategy to legitimize new violence}

\author{
Neyla Graciela Pardo Abril ${ }^{2}$ (iD) Camilo Alejandro Rodríguez Flechas ${ }^{3}$ (it) \\ Universidad Nacional de Colombia, Bogotá, Colombia. \\ ngpardoa@unal.edu.co
}

caarodriguezfl@unal.edu.co

\section{GACCESO ABIERTO / OPEN ACCESS}

Cita: Pardo Abril, Neyla Graciela, Rodríguez Flechas, Camilo Alejandro (2019). Representación mediática de inadecuación de la víctima. Estrategia legitimadora de nuevas violencias. Textos en Proceso, 5(2), pp. 1-26.

https://doi.org/10.17710/tep.2020.6. 1.1pardorodriguez

Editors: Esperanza Alcaide Lara, Universidad de Sevilla; Ana Pano Alamán, Università di Bologna

Recibido: 15/03/2020

Aceptado: 02/05/2020

Conflicto de intereses: Los autores han declarado que no poseen conflicto de intereses.

Copyright: ( ) Neyla Graciela Pardo Abril, Camilo Alejandro Rodríguez Flechas. Esta obra está bajo licencia Creative Commons Reconocimiento 4.0.

\section{Resumen}

El propósito de este estudio es determinar las representaciones mediáticas de la inadecuación en un conjunto de narrativas. Se estudia una muestra de cuatro storytelling del Especial de ElTiempo.com (2017) "Treinta encuentros con la paz". El objetivo del estudio es verificar las estrategias semiótico-discursivas apropiadas por el medio de comunicación y establecer la relación que se genera entre la formulación del sujeto inadecuado -víctima- y las formas de proponer su revictimización. Se formula una correlación entre la inadecuación social y la evaluación massmediática de carácter negativo, que implica legitimación de formas de violencia. El estudio propone la representación mediática de la inadecuación como parte de la estrategia de construcción de miedo. Se reconoce el efecto que procede de la mediatización y, en particular, se verifican las consecuencias socio

\footnotetext{
${ }^{1}$ El Grupo Colombiano de Análisis del Discurso Mediático (Colciencias A), a través de ONALME (Observatorio Nacional de Procesos de Memoria), trabaja con la red de investigación SPEME, sobre las memorias colectivas y los procesos de memorialización. Questioning Traumatic Heritage: Spaces of Memory in Europe, Argentina, Colombia-SPEME está financiado por el programa de cooperación Horizon 2020 de la Unión Europea y se desarrolla de manera conjunta entre la Universidad de Bolonia, la Universidad de Ámsterdam, la Universidad de Buenos Aires, la Universidad Nacional de Colombia, Fundación Campo di Fossoli, Museo Sitio de Memoria Esma y H401 (Project ID: 778044).

${ }^{2}$ Neyla Graciela Pardo Abril es Doctora en Filología-Lingüística Española. Profesora titular e investigadora del Instituto de Estudios en Comunicación y Cultura (IECO) y del Departamento de Lingüística, de la Universidad Nacional de Colombia. Investigadora sénior y líder del Grupo Colombiano de Análisis del Discurso Mediático (Colciencias) y del Observatorio Nacional de Memoria (ONALME). Actual vicepresidenta para las Américas de la IASS. Coordinadora SPEMEColombia.

${ }^{3}$ Camilo Alejandro Rodríguez Flechas es Lingüista de la Universidad Nacional de Colombia, Mg. en Análisis del Discurso de la Universidad de Buenos Aires; miembro del Grupo Colombiano de Análisis del Discurso Mediático (Colciencias). Miembro activo de ONALME (Observatorio Nacional de Procesos de Memoria), y de la red de investigación SPEME-Colombia.
} 
políticas, culturales y psicológicas que se instalan en las maneras como se construye la inadecuación de la víctima en la narrativa virtual. La reflexión conceptual procede de los trabajos más recientes que, sobre la visualidad gráfica, se han venido elaborando en estudios multimodales y multimediales, así como desde la semiótica visual que atraviesa los principios de la multimodalidad.

Palabras clave: inadecuación, miedo, percepción de evaluación negativa, mass media, storytelling, estudios críticos del discurso multimodal y multimedial (ECDMM).

\begin{abstract}
The purpose of this study is to determine the media representations of inadequacy in a set of narratives. A sample of four storytelling from the ElTiempo.com Special (2017) "Thirty encounters with peace" is studied. The objective of the study is to verify the semiotic-discursive strategies used by the media, and to establish the relationship that is generated between the formulation of the inappropriate subject -victim- and the ways of proposing their revictimization. A correlation is formulated between social inadequacy and negative mass media evaluation, which implies legitimization of forms of violence. The study proposes the media representation of inadequacy as part of a fear-building strategy. The effect of mediatization is recognized, and in particular, the socio-political, cultural and psychological consequences involved in building the victim's sense of inadequacy in the virtual narrative. The conceptual reflection comes from the most recent works that, on graphic visuality, have been elaborated in multimodal and multimedia studies, as well as from visual semiotics that crosses the principles of multimodality.
\end{abstract}

Keywords: inadequacy; fear; perception of negative evaluation; mass media; Storytelling; multimodal and multimedia critical discourse studies (MMCDS).

\title{
1. Representación mediática de la inadecuación de las víctimas
}

Se analiza, con carácter exploratorio, la manera como se construye mediáticamente el sentido de inadecuación social a partir de las formas como se representa "el modelo de víctima superada" en los storytelling del periódico Eltiempo.com (2017), “Treinta encuentros con la paz". Los estudios más recientes, en los que se relacionan factores psicosociales al fenómeno de la inadecuación (Caballo et al., 2018), permiten inferir que este fenómeno social refiere un conjunto de juicios $\mathrm{y}$ percepciones que, en relaciones diversas, evidencian fenómenos como el miedo y la ausencia de autoestima. Desde este punto de vista, los juicios y las percepciones materializan formas de valoración que una persona realiza sobre sí misma. La psicología social ha señalado que la autoestima, y en general, los sentimientos, así como todas las percepciones que un sujeto elabora sobre sí mismo, son esencialmente formas de evaluación de relativa estabilidad, y que se vinculan a los contextos sociohistóricos, en los que las personas desarrollan sus actividades y relaciones sociales (Alessandri et al., 2015). La adecuación o inadecuación social han sido consideradas como factores constitutivos de la autoestima. En este trabajo los procesos evaluativos que manifiestan las víctimas o que le son atribuidos, son un tipo de representaciones que formula el storytelling para evaluar la experiencia vital de una persona en el marco del conflicto armado colombiano, y que se 
proponen desde el rol de autoridad que despliega el medio de comunicación en relación con la situación de las víctimas en la etapa del postacuerdo.

La representación de la inadecuación massmediática tiene un efecto nocivo para las comunidades a las que se dirige, en la medida en que los condicionamientos que determinan la autopercepción y la percepción del otro implican aspectos de orden cognitivo, emocional y accional, formulando que la acción social humana responde a factores que determinan inadecuación, autoestima y miedo. Se pueden presentar, como consecuencia, procesos de revictimización simbólica por parte del medio que orientan la acción social de los individuos y contribuyen a gestionar grados de vulnerabilidad, opciones de respuesta individual y producir estados de tensión social que se derivan de la construcción sígnica de la inadecuación. Esta (re)victimización mediática implica los ámbitos afectivos, emocional y fisiológico, por lo que se hace necesario entender la construcción de los storytelling como procesos semiótico-narrativos encarnados que producen efectos en la elaboración del tejido social en el país.

\section{Construcción multimodal y multimedial en el Storytelling}

Los storytelling objeto de este análisis se caracterizan por recuperar los factores esenciales de la comunicación mediática contemporánea, por lo que no solamente cabe destacar que se estructuran a través de modos semióticos, sino que se soportan tecnológicamente en la web, dando cuenta de un uso múltiple del lenguaje que en el marco de la acción comunicativa genera unidades de sentido para ser interpretadas desde puntos de vista diversos. En Pardo Abril (2020), se señala que el carácter visual de las narrativas mediáticas se articula en dos factores fundamentales de la comunicación digital; por una parte, el sentido que se instala al seleccionar un soporte específico usando técnicas digitales y, por otra parte, el sentido que se genera de la potencialidad del soporte tecnológico para garantizar la selección amplificada de recursos semióticos disponibles. De esta manera, el proceso de interpretación sucede sobre una unidad típicamente multimedial y multimodal.

El carácter visual de las narrativas mediáticas que se concretan en el storytelling permite observar la preponderancia de la visualidad que se formula al narrar y diseñar lo que se expresa. En esta perspectiva, Ledin y Machin (2018) señalan que la mirada más totalizadora del hecho discursivo impone reconocer, entre otros fenómenos, cómo se articulan los distintos sistemas semióticos, qué implicaciones tiene el proceso de selección de los recursos semióticos y cómo incide el género en la construcción conceptual de la sociedad que queda representada discursivamente. El discurso es una unidad semiótica que se explora desde las huellas semántico-pragmáticas y sus relaciones, las cuales orientan el proceso inferencial propuesto en la unidad discursiva. En esta perspectiva, el análisis del tejido semiótico tiene como núcleo verificar la visualización propuesta de unidades significativas materializadas en los distintos sistemas semióticos; de esta manera, el proceso interpretativo integra los modos de expresión, el soporte y el compromiso interactivo que se estructura entre quien produce y comprende lo expresado. En el proceso de interacción surgen las perspectivas posibles sobre lo que se expresa; por lo tanto, los estudios multimediales y multimodales exigen el desentrañamiento de las ideologías, los valores, las actitudes y las creencias a través de las cuales se formula la mirada sobre la realidad social representada. 
Dado que la comunicación contemporánea ha desarrollado formas de visualización discursiva, en múltiples tipos de situaciones comunicativas articuladas a diferentes tecnologías, se parte del presupuesto de que los Estudios Críticos del Discurso Multimodal y Multimedial (ECDMM) asumen una amplia gama de recursos tecnológicos de carácter digital y analógico que van desde la web a impresos gráficos distribuidos digitalmente y propuestos a comunidades perfiladas, pero no claramente identificadas, de interlocutores. Por esta razón, el medio o soporte se constituye en la primera fuente para la mirada analítica y crítica del material semiótico que porta. Este punto de partida exige que el procedimiento analítico se centre en el conjunto de intereses que gestan las expresiones visuales producidas para amplios sectores poblacionales (Pardo Abril, 2016).

En el caso de los storytelling, se propone que constituyen un tipo de visualización con temporalidades y espacialidades distintas, en la que se articulan funcionalmente imágenes fijas, móviles, infografías y uso de lengua. Esto genera que el proceso interpretativo involucre diversos compromisos de sus interlocutores tanto para gestionar el recorrido de la unidad visual, como para transitar las distintas propuestas interactivas formuladas como rutas para la comprensión e interpretación de lo que expresa la narrativa mediática, y que se ofrecen como una macro unidad de significado para su interpretación. Al circular por la web, se prevén los modos semióticos que circulan en relación con las propiedades y potencialidades del soporte.

Las narrativas mediáticas que circulan por ElTiempo.com son unidades semiótico-discursivas cuya espacialidad es de doble dimensión: el narrador propone una temporalidad dinámica que alterna permanencia e instantaneidad, formulándose desde el punto de vista de un sujeto omnisciente; $y$, el interlocutor que testimonia asume en el proceso de su producción un carácter de participante inmersivo, mientras se diseña un interlocutor interpretante que tiene un rol de observador performativamente orientado. En este sentido, también el soporte tecnológico está diseñado para proponerse como parte de una unidad de significación (Bateman et al., 2017).

Uno de los procesos que se rastrean en el storytelling es la configuración de los actores discursivos, entendiendo estos como los participantes activos de la interacción, los cuales "desempeña[n] roles discursivos y construye[n] como sujeto social una imagen de sí, del otro y de la realidad" (Pardo Abril, 2007, p. 132). Un actor discursivo es un ser activo con capacidad de agencia a través de la cual elabora significado y ayuda a la formulación de la realidad social. Esta agencia se construye a partir de la subjetivación y de las expresiones identitarias, resultado de "[...] procesos tanto simbólicos como históricos contingentes, en los que intervienen tanto las significaciones como las experiencias sedimentadas en torno a aquellos" (Busso, Gindin y Schaufler, 2013, p. 347). Estos dos aspectos se activan en el marco de unas prácticas estratégicas donde se pretende construir una única perspectiva válida en torno a un fenómeno (Leipold y Winkel, 2017); para ello se utilizan una serie de recursos como puede ser la despersonalización del actor para validar un estado de cosas o determinar un curso de acción.

Dentro de la construcción del actor discursivo y su capacidad de agencia no solamente se hace una representación de un 'nosotros', sino también se formula un 'otro', especialmente en territorios de conflicto donde intervienen y se activan discursos relacionados con la securitización. Como señala Rumelili (2013) la búsqueda de seguridad física implica tanto el nombramiento como la identificación 
de amenazas para la supervivencia, que a menudo involucran la securitización de un otro, y el desarrollo de medidas para defender al yo contra esas amenazas. Al proponer al otro como amenaza se ejerce una violencia simbólica, sustentada en recursos como la ontologización del rol y el estatus del sujeto o el uso de estereotipos alrededor de sus axiologías, creencias y hábitos.

En el marco del conflicto armado colombiano, la representación del otro como amenaza se ha constituido alrededor de múltiples narrativas mediáticas sobre los valores y las acciones de los grupos guerrilleros, especialmente las FARC. Trabajos como el de Olave (2014) revelan los ethos construidos alrededor de estos grupos, mientras investigaciones como la de López-López et. al (2014), resaltan las estrategias utilizadas para caracterizar a los grupos ilegales entre las cuales se incluyen deshumanización y la caracterización negativa de sus acciones. A pesar del proceso de desmovilización y reintegración producto del Acuerdo de Paz entre el Gobierno y las FARC (2016), los excombatientes, mediáticamente, aún son percibidos como guerrilleros y son elaborados representacionalmente como una potencial amenaza para la reconstrucción del tejido social y la seguridad de las poblaciones cercanas a donde se encuentran las Zonas Veredales Transitorias.

Esta indagación parte del supuesto de que la representación discursiva del miedo produce resultados sociales perjudiciales, en este caso, no solo para los distintos actores del conflicto, sino para la sociedad en general. Se ha señalado que el miedo produce aislamiento y comportamientos protectores que incluyen restricciones de movilidad y socialización limitada, que pueden erosionar e impedir la satisfacción con la vida y participar de las condiciones de dignidad y derecho de quienes son victimizados. Shrum (2002) ha sugerido que la percepción del miedo implica que quienes se apropian de la representación lo hacen en distintas dimensiones: (1) cognitiva, en la cual, para el caso del conflicto armado colombiano, se centra en la estimación del sujeto y la sociedad, sobre la probabilidad de sufrir daño y sufrir procesos de victimización; (2) emocional, que se centra en los sentimientos de las personas sobre el sentido y la percepción mediáticamente, negativa acerca de la condición de víctima y/o victimario; y (3) el miedo como una forma de proceder, centrada en cómo las personas responden a esta representación o al riesgo percibido de victimización. En este orden de ideas, el miedo se construye gestionando mediáticamente percepción de vulnerabilidad frente al daño eventual al que se somete al sujeto victimizado, formulado en noticias virtuales, narrativas de ficción, o la construcción de casos espectaculares, donde el proceso de distribución garantiza que las personas aprendan de eventos o potenciales eventos que han ocurrido a nivel local o nacional.

Un elemento que surge en la construcción discursiva de los storytelling se relaciona con las representaciones que hacen los medios de las víctimas y de los victimarios. Los medios de comunicación producen un imaginario sobre los actores del conflicto, donde no son considerados plenamente como actores discursivos, es decir, como sujetos con voz capaces de construir una imagen de sí. Esto se extiende no solamente a nivel de lo dicho, sino a nivel de lo gráfico, donde el medio propone la identidad física funcionalizada a los propósitos comunicativos de la narrativa general del medio. Esto constituye un problema de carácter ético que surge de la tensión entre el derecho a la intimidad del sujeto y la búsqueda por una verdad histórica, que es resuelta en el proceso de diseño del storytelling a través del uso de los recursos de espectacularización y de mitigación. Se configura así un 'ver y no ver' propio del impresionismo, donde la composición es resultado de la percepción 
subjetiva de la realidad (Stoichita, 2005); en este caso, el punto de vista del periodista es socializado como un análisis objetivo de la realidad.

Esta estrategia de subjetivación-objetivación se refuerza a través de la selección de algunas víctimas y victimarios para la realización de los storytelling, ya que su punto de vista constituye un testimonio relevante para entender contradicciones y ambigüedades en los procesos y acciones en el conflicto. Al estar enmarcado dentro de un dispositivo de poder, la mirada es utilizada para legitimar la gestión de la memoria oficial que hace el medio de comunicación, atendiendo los intereses y/o los lineamientos que los gobiernos de turno definen para una etapa como la del postacuerdo.

Se activa por lo tanto el dispositivo mediático como un recurso de orden económico-político con clara función orientadora de la acción social. El dispositivo se entiende como "un conjunto de praxis, de saberes, de medidas y de instituciones cuya meta es gestionar, gobernar, controlar y orientar [...] los comportamientos, los gestos y los pensamientos de los hombres" (Agamben, 2011). La tarea del medio como dispositivo, siguiendo lo planteado por Deleuze (1990) sería plantear unos regímenes de visibilidad que serían a través de los cuales ocurre ese 'ver y no ver', donde se implican los principios éticos fundamentales de las instituciones socializadores en las sociedades contemporáneas.

\section{Formulando una ruta}

El proceso analítico e interpretativo se aplica al especial de ElTiempo.com (2017) "Treinta encuentros con la paz" y se limita a la observación sistemática de cuatro narrativas cuya relevancia procede del manejo que genera el medio de comunicación sobre la imagen/caracterización de la víctima representada. Los criterios de selección del corpus implican los años 2016 y 2017, teniendo como eje nuclear la firma del acuerdo de paz en noviembre 24 de 2016. En este periodo, el medio de comunicación publica las narrativas mediáticas objeto de este análisis. Interesa revisar la relación que ocurre entre las representaciones mediáticas formuladas por el medio y a su vez la que lleva a la construcción de un sujeto inadecuado, que se enmarca en los condicionamientos propios del conflicto armado colombiano. En el proceso de descomposición analítica, la representación de la inadecuación produce un conjunto de idearios tendentes a naturalizar formas de revictimización.

La posición epistémica y el método cohesionan los ECDMM anclados al paradigma cualitativo, cuyo propósito es encontrar relaciones de significado que permitan la generación de inferencias, dando cuenta de los recursos semióticodiscursivos implicados y permitiendo derivar consecuencias de orden sociocultural del discurso analizado. El procedimiento analítico se compone de tres fases, que se han sido desarrolladas a lo largo del programa de trabajo desarrollado por Pardo Abril (2014, 2017, 2010): descripción, análisis e interpretación. La primera fase, busca determinar cómo se construyen los conocimientos en torno a las relaciones que se generan entre la formulación mediática del sujeto inadecuado, víctima del conflicto armado, y las formas como los medios construyen ejercicios de revictimización. En esta correlación se valora axiológicamente la legitimación con sus consecuencias para el escenario de posconflicto.

Se parte de un proceso de observación inicial del corpus para identificar categorías y establecer relaciones intercategoriales que permitan inferir un conjunto de hipótesis centradas en aspectos específicos del fenómeno socio-discursivo. En 
este procedimiento descriptivo se analizan las características del discurso a nivel multimodal y multimedial; es decir, hay un reconocimiento de los modos semióticos que son puestos en juego y del soporte tecnológico y sus potencialidades de significación dentro del marco cultural.

Se adopta para este proceso la herramienta N-Vivo 12 que permite trabajar con el corpus de manera más amplia, ya que se pueden elaborar taxonomías, relaciones y comentarios sobre los discursos en distintos niveles: lingüístico, visual y auditivo. N-Vivo 12 facilita realizar la identificación de fragmentos discursivos relevantes, anotar los marcadores visuales de color y otros modos con el propósito de establecer las inferencias que soportan el procedimiento analítico posterior y aplicar teorías, categorías y conceptos. En este caso, se examina la manera como el medio propone sígnicamente la comprensión de los actores discursivos, especialmente en búsqueda de determinar la manera como se elabora la noción de víctima, tanto en el discurso visual-gráfico como en el visual lingüístico.

La segunda fase es un recorrido analítico que se hace después de explorar el corpus. Se verifican los recursos y las estrategias semiótico-discursivas que dan sentido a los patrones semióticos hallados. En esta etapa se perfila la relación que va del discurso a la sociedad y viceversa, ya que se busca la identificación de los intereses, los propósitos comunicativos y los tipos de representación social formulados. Se establece la manera en la que la articulación de los modos semióticos y las estrategias producen efectos de sentido concretos, dentro del marco de unos valores y axiologías propuestos en el discurso objeto de análisis.

En la última etapa se produce una correlación de los resultados hallados con el marco contextual, para determinar los usos sociales y el tipo de relaciones de poder que se pretenden estabilizar o con los que se pretende generar ruptura. En esta etapa se tiene en cuenta que los discursos están inmersos en una red de prácticas y de instituciones que determinan de manera parcial su incidencia en las formas de conocer de la comunidad, y consecuentemente en la manera de orientar la acción social. En este caso, la narrativa mediática puede tener o no la potencialidad de romper las maneras de visibilizar o invisibilizar las representaciones en torno a los sujetos victimizados, los cuales han sido tradicionalmente considerados por las élites político-económicas como una amenaza, fomentando cotidianamente la construcción de la diferencia y la activación de emociones como el miedo. En esta fase, se formulan implicaciones o consecuencias socioculturales de las representaciones sociales, con el fin de pensar en posibles alternativas que contribuyan la reconstrucción del tejido social, especialmente en la coyuntura actual del posconflicto en Colombia.

En este procedimiento, por lo tanto, se ponen en relación directa las estructuras socioculturales, el conjunto de actividades cognitivas representadas y las formas como queda cognitivamente propuesto el escenario social en el mundo mass mediático. Esta manera de proceder da paso a la explicitación de los propósitos comunicativos, las racionalidades, las acciones y, de manera particular, el conjunto de asuntos que definen la agencialidad y el rol de quienes son representados en el marco del conjunto de creencias, axiologías e ideologías que se instalan sistemáticamente en las unidades simbólicas que determinan la esencialidad del discurso. 


\section{Los juegos del miedo mediático: de la víctima a la revictimización; de víctima a victimario; víctimas y victimarios revictimizados}

Los storytelling objeto de análisis, a través del proceso de organización semiótica que implica una articulación entre discurso escrito e imagen, narran procesos de vulnerabilidad en los que la victimización pasada se fragmenta o se elide para trasladar el fenómeno a una narrativa que va de lo verosímil a lo ficcional, con el propósito de construir un modelo de víctima superada y formulada como prototipo para ser replicado. Las maneras de representar las emociones, los sentimientos que alertan al sujeto sobre la necesidad de alcanzar un punto de éxito, o la expectativa de mantenerse en condición victimizada, construye la percepción de inadecuación social.

Aunque se pueden encontrar diferentes estudios sobre el papel de los medios de comunicación en la construcción del miedo y la percepción de victimización, no hay una reflexión que permita explicitar las implicaciones que tiene el storytelling en la construcción de la inadecuación social. Además del juego con las voces de las víctimas y asociado a la idea de que el mercado es nuclear para la construcción social, se elabora la idea de que ciertos sectores poblacionales no se adecúan a los valores y axiologías propugnados e instaurados hegemónicamente. Estos no solo se sustentan en planteamientos neoliberales, sino también en representaciones judeocristianas y en prejuicios de clase que fomentan la subalternización de conjuntos de personas con visiones de mundo alternativas: esto incluye a todos los actores del conflicto, y a sus víctimas. Este proceso de exclusión socio-discursiva se elabora desde el planteamiento de una noción de 'inadecuación' en la cual los miembros de una comunidad determinada no tienen derecho a ejercer su ciudadanía al no alinearse con los constructos y el funcionamiento de las instituciones sociales que regulan la vida social.

\subsection{La inadecuación, ¿una decisión personal?}

La inadecuación se produce por la generación de unos estereotipos y arquetipos sociales creados dentro de un imaginario común que no corresponden con las necesidades efectivas de las comunidades. El recurso de la exclusión es el ocultamiento o la invisibilización, para lo cual el medio de comunicación activa un marco donde se pretende mostrar que estas comunidades se auto marginan de la sociedad, como si tomaran la decisión de no participar colectivamente del entorno social que los rodea. Para ello, se les presenta como personas con volición, lo cual incluye voluntad de fuga o una búsqueda de huir de los lugares que habitan, lo cual en la perspectiva de Shrum (2002) expresa miedo.

Uno de los propósitos principales de las narrativas del especial realizado por ElTiempo.com es construir la idea de que ciertos sectores poblacionales no se ajustan a las axiologías e ideologías propugnadas desde las élites. En la sociedad colombiana el marco de valores está sustentado principalmente en planteamientos neoliberales y en representaciones judeocristianas, a partir de los cuales se crean una serie de arquetipos o modelos de sujeto social cuyo discurso y acción está legitimado. Esto a su vez implica la construcción de un 'otro' que no es validado socialmente y que es subalternizado por poseer una visión de mundo alternativa. Este proceso de exclusión socio-discursiva se elabora desde el planteamiento de una noción de 'inadecuación' en la cual los miembros de una comunidad determinada 
no tienen derecho de ejercer plenamente su ciudadanía al no alinearse con los constructos y el funcionamiento de las instituciones sociales que regulan la vida social como el Estado o la Iglesia. En nuestra cultura las figuras sobre la cual se han ejercido sistemáticamente procesos de vejación han sido comunidades victimizadas como los indígenas, los afrocolombianos, los campesinos y los sujetos LGTBI entre otros-, quienes incluso han sido sometidos a procesos de revictimización, tanto por la falta de una reparación y restitución efectiva de derechos, como por la aplicación de una violencia simbólica, que se ve expresada tanto en la cotidianeidad como en los discursos mediáticos.

El storytelling "LGBTI, las víctimas que ya no quieren ser invisibles" trata de establecer un cuadro visual-verbal en el que se plantea que las personas que pertenecen a este tipo de población poseen características negativas, acometen acciones erróneas o tienen responsabilidad directa por su condición de víctima. Esta forma de proceder del medio se verifica desde el propio titular donde se recurre a un proceso de ontologización ya que se adjudica la condición de invisibilidad directamente a la víctima y no a un tipo de violencia estructural en el marco de conflicto armado donde la performatividad de los sujetos LGBTI ha sido invisibilizada. Esto se complementa con el ante titular en el que se usa la cuantificación para determinar el número relativo de personas LGBTI que han sido víctimas del conflicto con respecto al número total de personas que se reconoce parte de esta comunidad. El uso de la estadística " 2.515 víctimas del conflicto se reconocen como personas LGBTI" funciona como una manera de invisibilización en sí misma, ya que desconoce que existe un gran número de sujetos sociales que a causa de amenazas o de estigmatización social no hace un proceso de reconocimiento público de su orientación de género.

Inmediatamente después del titular se encuentra la imagen principal donde aparece el protagonista de la narrativa, Dúmar Rico, víctima de desplazamiento forzado quien es señalado de ser víctima por su condición de género y quien ha tenido que abandonar su lugar de origen, trasladándose a diferentes núcleos urbanos. En la imagen, por el tipo de encuadre, se crea una representación fragmentaria de la víctima y se la muestra como una ejemplificación del proceso de inadecuación a la urbe. Por un lado, la víctima es representada vestida en relación con un tipo de sector sociodemográfico específico que no es característico de la mayoría de la población urbana, lo cual se complementa con otros elementos de su presentación como el cabello o la barba que funcionan como marcadores que indican una falta de cuidado personal. Por otro lado, esta inadecuación no solo se ve representada en la víctima que aparece como foco de la imagen sino también por los elementos que aparecen de manera periférica: se halla la presencia de un tubo que ejerce indicialmente como una barrera, un límite que aún tiene que atravesar para lograr camuflarse con la ciudad; también en el plano del fondo, tapado por la naturaleza se pueden identificar edificaciones propias de las zonas urbanas como son los edificios, que sumado a los otros elementos mencionados dan cuenta de un proceso de exclusión. Las dos líneas de colores paralelas añadidas a la imagen permiten mostrar tanto la orientación de la misma como la construcción de límites: la azul que es el límite físico y la roja que es el límite simbólico que separa el primer plano del segundo, donde se halla lo deseado. 


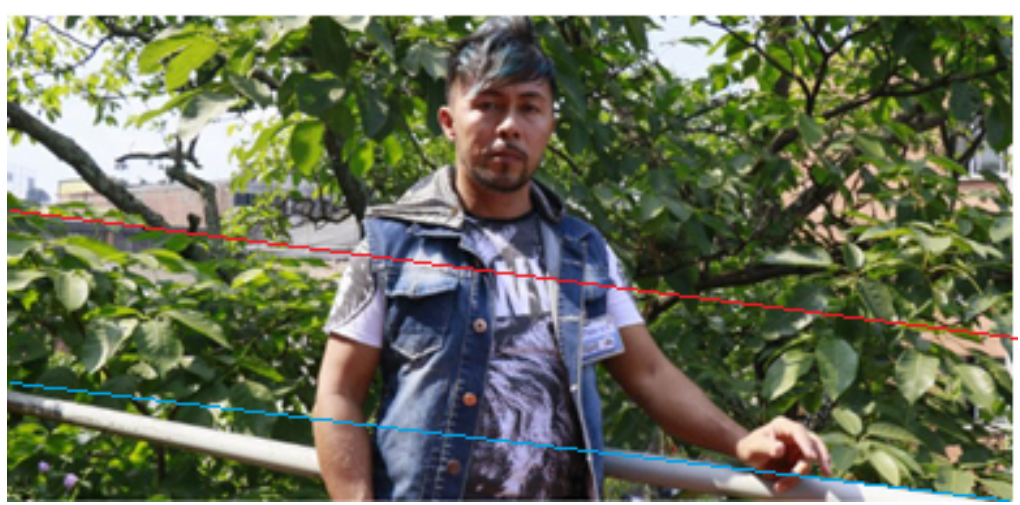

Ilustración 1. "LGTBI, las víctimas que ya no quieren ser invisibles" (ElTiempo.com, 31 de mayo de 2017).

En el cuerpo de la narrativa aparece una serie de fenómenos que amplifican todos los sentidos propuestos en el titular y la entradilla. En la primera parte, el periodista se propone como un sujeto omnisciente que conoce la historia de Dúmar, incluso sus estados psicológicos mientras se desarrolla la acción: cuenta la forma en que salió de su vereda, donde era un participante asiduo de las actividades comunales, y en que se trasladó a diferentes ciudades a causa de las amenazas de paramilitares. Se propone el hecho de que la víctima se mimetiza con la ciudad como mecanismo de protección y como fórmula para participar de la economía:

Sabe sembrar café, cosecharlo, limpiarlo, trillarlo y todo el proceso que termina en la bebida por la cual son conocidos los colombianos, pero en la urbe le tocó aprender varios oficios y terminó dedicado a la belleza y al cuidado personal en una peluquería que tiene en la parte frontal de su casa, porque lo mejor para su seguridad era mimetizarse entre los transeúntes y ser invisible (ElTiempo.com, 31 de mayo de 2017).

En este fragmento del storytelling, el periodista produce una ironía "terminó dedicado a la belleza y al cuidado personal" cuando, a través de la fotografía fija, produce un punto de vista que no necesariamente es el suyo, formulando una disociación y burla que el lector común recupera del implícito formulado; y una serie de modalizaciones tanto epistémicas como apreciativas, a través de las cuales construye un marco de legitimación, siendo el periodista la figura de autoridad que permite valorar, por ejemplo, qué es lo mejor para su seguridad. En esta parte se repite constantemente este ejercicio de utilizar el juicio de valor para hacer ponderaciones sobre la situación de la víctima. El caso más claro ocurre cuando se utiliza la siguiente metáfora: "[...] puede decir que ser gay lo hizo blanco del hostil poder que los grupos al margen de la ley tenían en su territorio". Siguiendo lo planteado por Lakoff y Johnson (1986), se puede determinar que esta es una metáfora ontológica en tanto sustituye una entidad humana por un objeto; sin embargo, también se puede pensar que posee un sentido orientacional en tanto el concepto de "blanco del hostil poder" implica que el sujeto de poder haga una trayectoria de mirada hacia el blanco. La función de esta metáfora es ocultar a los responsables del desplazamiento del que es víctima Dúmar, además de responsabilizarlo por su misma condición de víctima.

En el resto de este discurso continúa apareciendo la estrategia de legitimación por autoridad, definida por Van Leeuwen (2007) como la referencia a la tradición o alguna instancia institucional que permita ejercer un proceso de validación de conocimiento. Se utilizan las cifras y las voces de documentos oficiales para 
legitimar la revictimización de las personas LGTBI; y se hace una presentación de cifras de víctimas que se acompaña con el uso de porcentajes para determinar un dato relativo de las denuncias. En este fragmento de la narrativa ocurren varias substancializaciones, es decir, los sujetos y los lugares son formulados como organismos vivos que sufren procesos: "El desplazamiento, las amenazas y los homicidios son los hechos que más han padecido estas personas", "[...] municipios de Bolívar, Cundinamarca, Sucre, Atlántico, Antioquia, Valle y Magdalena, zonas golpeadas por el conflicto". La consecuencia de contextualizar de esta manera la situación es proponerla en términos de una acción física y no en relación directa con la política pública que deben implementar las distintas instancias gubernamentales para garantizar que las dichas acciones contribuyan para la transformación de la situación representada.

Se finaliza despotencializando cualquier noción positiva alrededor de las víctimas ya que son perfilados como una amenaza tanto para su entorno cercano, como para la sociedad en general. A través de la legitimación por autoridad, se le da voz a Mauricio Garcés, enlace LGBTI de la Gobernación del Valle, quien propone a las víctimas como sujetos sin conocimientos por haber venido de un contexto rural, y como amenazas, atribuyéndoles a las víctimas su condición: "Hay personas que sienten que su orientación sexual los hizo responsable del daño que han sufrido y naturalizan esa violencia, creen que es su culpa y que por eso pusieron en riesgo a su familia", puntualiza. Con esto se observa que el storytelling, más que una forma de reivindicación y visibilización de las víctimas, contribuye a un proceso de señalamiento e identificación de personas, que puede ser perjudicial tomando en cuenta la coyuntura actual donde sigue existiendo el conflicto armado.

\subsection{Unificar el saber, el ser y el hacer, ¿una alternativa en la construcción de paz?}

En "Los embera-katío vuelven a su tierra ancestral", la representación de la inadecuación de la comunidad se propone como condición para la intervención del Estado, en el marco de un desplazamiento forzado colectivo, como uno de los factores con mayor índice de afectación sobre la población referenciada. Los factores de inadecuación se relacionan esencialmente con su condición de víctimas de desplazamiento forzado en la ciudad de Medellín proponiendo su presencia como sujetos vinculados a estados de precariedad, vicio y mendicidad, a través de cuyos marcadores semióticos se infiere revictimización. En este marco, el storytelling, construye la representación del temor de los sectores involucrados diseñando evaluación social negativa, para los miembros de la comunidad. Se examinan los marcadores semánticos discursivos que se asocian a ejes conceptuales como el ser, saber y el hacer, a través de los cuales se gesta tensión social. La ansiedad social se expresa como miedo o la sensación de incomodidad que se representa como acción social. El sentido de subalternización y violencia simbólica, así como la negación de los derechos, posibilita representar mediáticamente a la comunidad emberakatío, como sujetos que no se adaptan a los entornos sociales. En esta perspectiva, el medio y las voces de quienes se proponen con rol institucional, explicitan que no hay cambios en su rendimiento socio cognitivo en términos de su presencia e interacción con el entorno urbano.

Desde la psicología social, Muro y Jeffrey (2008) señalan la adecuación cognitiva implica procesos de aprendizaje en interacción con otros, en contextos específicos. Dentro de estos parámetros se generan cambios en los procesos de 
apropiación de saberes y se adoptan acciones y formas de proceder social, especialmente a través de experiencias positivas que sean articuladoras de intereses colectivos. En este sentido, la cognición tiene un rol nuclear en la apropiación de saberes orientadores de la acción y la adecuación del sujeto a los condicionamientos socioculturales. En sentido similar, se evidencia que los procesos observacionales son fuente de aprendizaje y formas de conocer, que pueden determinar cambios de comportamiento humano, los cuales implican expectativas de consecuencia y de acciones futuras a partir de la experiencia pasada y presente, en el orden de lo individual y lo colectivo; estas expectativas inciden en la toma de decisiones junto con los efectos que se derivan de la no satisfacción de las expectativas, creando las condiciones de inadecuación social.

Recursos como la polifonía, la metáfora, la cuantificación y estrategias como la legitimación por autoridad aparecen en la narrativa "Los embera-katío vuelven a su tierra ancestral" en donde se revictimiza a una comunidad indígena. Los indígenas han sido víctima de fenómenos como desplazamiento forzado, usurpación de tierras y asesinatos sistemáticos. Datos sobre la Organización Nacional Indígena de Colombia (ONIC) muestran que "entre 1974 y 2009 hubo 2.351 asesinatos políticos contra indígenas en el país y el 80\% fue a partir de 1999" (Archila et al., 2014). Además de la violencia física y la violencia estructural también están sujetos a una violencia simbólica que se materializa en los discursos mediáticos donde constantemente son invisibilizados sus derechos y donde son mostrados como comunidades que no se adecúan a los escenarios sociales tradicionales como las ciudades, de donde han sido excluidos. Las organizaciones indígenas han denunciado constantemente acciones de partidos políticos con ideología conservadora, manifestando los ataques de los que son víctimas. En la prensa colombiana se pueden verificar discursos en los cuales claramente los pueblos indígenas son victimizados, marginalizados y acusados por las élites por ser colaboradores de grupos al margen de la ley.

El storytelling mencionado se centra en la situación de los indígenas emberakatío, específicamente aquellos establecidos en el resguardo del Alto Andágueda en el departamento del Chocó. La mayoría de los miembros de esta comunidad ha sido desplazada no solo por las acciones de las guerrillas de las FARC-EP y del ELN, sino también por una guerra en la que han estado involucrados otros actores como los paramilitares, los terratenientes antioqueños y el Estado, especialmente a través de la concesión de territorios para las actividades de explotación minera. Los miembros de esta comunidad han sufrido violaciones y abusos que incluyen: "ocupación armada, tortura, control social, reclutamiento forzoso de niños, violación sexual, asesinatos, atentados, amenazas, desplazamientos forzados y utilización como escudo" (CINEP, 2015, p. 20). A modo de reparación y restitución, el gobierno ha organizado en varias ocasiones planes de retorno para el regreso de los embera katío a sus territorios ancestrales siendo la última de estas durante el mes de noviembre de 2016 donde regresaron de la ciudad de Medellín.

La narrativa "Los embera katío vuelven a su tierra ancestral" contribuye a construir la identidad narrativa de esta comunidad, entendiendo la identidad narrativa como la manera en el que el sujeto construye un imaginario de sí mismo a través de valores y acciones representadas y conjugando diferentes temporalidades y subjetividades al mismo tiempo. Para ello se acude a construir un paisaje semiótico que representa la manera cómo los miembros de estas comunidades interactúan tanto con el entorno de las zonas urbanas como con su lugar de origen, 
tratando de construir la imagen de los indígenas como personas inadecuadas. En la imagen 2, aparecen las víctimas retornando a su territorio ancestral: el plano general hace que se difumine el sentido de la víctima y se cree visualmente una densidad de la desorganización que se ve reforzada por la presencia de sacos de color blanco, que por lo indicado en la narrativa se puede inferir que son los implementos de aseo y las ayudas estatales.

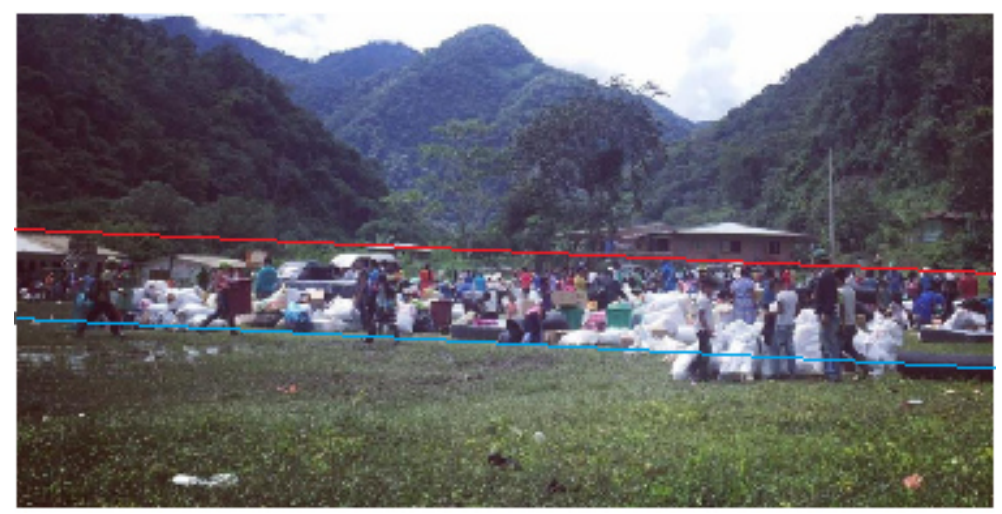

Ilustración 2. 'Los embera-katío vuelven a su tierra ancestral' (ElTiempo.com, 20 de mayo de 2017).

Tomando como marco de referencia la teoría de la imagen propuesta por Kress y Van Leuween (1996) la naturaleza y el paisaje armónico se encuentran en el plano de lo ideal, mientras los indígenas, las ayudas y el suelo que presenta irregularidades se proponen en el plano de real, produciendo la idea de lo negativo, enfrentado con lo estéticamente ideal. En el discurso se puede observar una búsqueda por la construcción de un paisaje abigarrado cuya función es justificar la intervención de las entidades gubernamentales locales, para desarrollar proyectos que traten de asimilar el paisaje de la comunidad al de la ciudad. Al igual que en el análisis de la narrativa anterior, las dos líneas paralelas permiten mostrar los vectores de orientación de la imagen: la línea roja divide lo terrenal de lo sagrado y lo deseado y la línea azul permite delinear cuál es la parte de la imagen con mayor densidad visual.

El storytelling está construido como un género híbrido integrando elementos de la crónica para contar el día del regreso de la comunidad, con elementos de informe y de entrevista, todo ello con el propósito de justificar los valores y la identidad propuestas alrededor de los embera-katío. Se evidencia un fenómeno de narrativización que busca idealizar la situación de regreso de los indígenas; para ello, se hace uso de marcadores emocionales que buscan apelar a los sentimientos del interlocutor:

Entre el llanto y la emoción de retornar a su tierra de la que nunca debieron haber partido, los indígenas, con sus rostros pintados y sus más coloridas prendas, cargaron vajillas, ollas, utensilios de cocina, colchonetas, sábanas, cobijas, toldillos, canecas, herramientas, mercado y dinero que les entregó la Alcaldía de Medellín y la Unidad de Víctimas para su manutención durante los primeros días de regreso (ElTiempo.com, 20 de mayo de 2017).

Además, esta cita ubica a las entidades oficiales dentro del paradigma del padre benefactor que entrega dádivas para el bienestar de la comunidad; el objetivo de esta representación es ocultar el hecho de que los organismos locales no dieron las suficientes garantías a este pueblo victimizado para el sostenimiento de la 
comunidad dentro de la ciudad. Se apela a la presentación positiva del regreso, funcionalizando la voz de las personas de la comunidad victimizada y sus representantes, y de miembros oficiales como la alcaldesa de Bagadó: "Y los veía animados, sin ninguna tristeza de dejar la ciudad, porque ellos siempre van a querer regresar a su territorio. El ambiente era de retorno, de estar volviendo a casa".

El representante embera ${ }^{4}$ Queragama denuncia los distintos tipos de violencia y las condiciones que determinaron su estado de inadecuación en la ciudad. El recurso central utilizado es la metáfora del 'infierno', remarcando las condiciones precarias en las cuales tuvieron que vivir:

"Vivir en la ciudad sin casa, sin agua, sin cobija y en plena calle parecía el infierno, no era vida. Algunos jóvenes fueron sometidos al vicio, pues convivieron con algunos drogadictos en Medellín. Cuando llegaron a la comunidad cargaban la mala yerba que daña la mente. La guardia indígena la descubrió, la decomisó y ellos fueron sancionados", comenta (ElTiempo.com, 20 de mayo de 2017).

La metáfora que se encuentra es de carácter estructural y se puede resumir a través de la expresión "la ciudad es un infierno", la cual está anclada a la tradición judeocristiana donde el infierno representa un lugar de perpetuo dolor y agonía donde se castiga a las personas que han cometido diferentes tipos de pecado, como se representa en la Divina Comedia. El uso del "infierno" como recurso implica dos elementos que están relacionados: la concepción del indígena como pecador, que sería la consecuencia del uso de sustancias alucinógenas, implicados en el nominal "mala yerba", y la atribución de vivir en condiciones precarias por culpa propia, ya que al igual que la concepción de cielo, el infierno implica el acceso por la voluntad de la persona que comete los malos actos.

Esta representación de la identidad narrativa es reforzada a través de legitimación por el uso de voces de expertos como miembros del gobierno local. La alcaldesa del municipio de Bagadó, Marinela Palomeque, realiza una contextualización de los hechos tratando de demostrar que el esfuerzo del retorno era una condición necesaria ya que no existió una adaptación de los indígenas a los valores de la ciudad, elidiendo las causas estructurales que determinaron el desplazamiento forzado de la comunidad embera-katío:

En Medellín, los indígenas fueron usados para toda clase de engaños por su vago conocimiento del español. "Los embera eran utilizados por organizaciones para protestar en las calles. Nos tocó seguirlos con una funcionaria de la Alcaldía de Medellín hasta un parque donde los tenían protestando por algo que ni entendían, llevaban pancartas que no sabían qué decían. Eso fue lo que generó el empeño de la institucionalidad para que regresaran", relata la alcaldesa Palomeque (ElTiempo.com, 20 de mayo de 2017).

Palomeque utiliza el recurso de la pasivización eran utilizados para elidir la agencialidad a los indígenas, desconocer su sabiduría ancestral y eliminar el valor de la lengua tradicional. Esta despotencialización del sujeto va en contra de la representación de las comunidades como pueblos de lucha y resistencia y se recontextualizan como sujetos sin volición propia. A esta representación subyace una garantía argumentacional que supone un grado de infantilización del indígena,

\footnotetext{
${ }^{4} \mathrm{El}$ pueblo embera es una comunidad indígena ubicada en las regiones suroccidental y centro de Colombia, principalmente en la zona pacífica. Según el Ministerio de Cultura colombiano, existen subgrupos dependiendo las variaciones dialectales, culturales y geográficas: chamí, katío y eperara siapidara. Los embera katío habitan en municipios de los departamentos de Chocó y Antioquia.
} 
la cual implica "una lectura evolucionista del ser humano: el sujeto infantilizado carece de los elementos necesarios para ser un sujeto completo" (Fornero y Artaza, 2018), y por tanto depende de lo que haga otro.

Al igual que con el storytelling sobre la comunidad LGTBI, otra forma de generar el sentido de inadecuación y configurar la identidad narrativa de los indígenas es valorizando positivamente los elementos que hay en las zonas urbanas en contraste con los que las comunidades poseen en sus lugares de origen. La alcaldesa Palomeque procura mostrar que se están desarrollando proyectos para llevar servicios y bienes que son propios de la ciudad como electricidad e infraestructura, sin tener en consideración si estos elementos son prioritarios para la forma de vida de la comunidad embera-katío del Alto Andágueda y si estos servicios se han consensuado con la comunidad: "Me parecería muy importante que esos derechos que a veces se les restituyen, más que darles alimentos, se les pudiera reconocer con el trazo de una vía".

También, al igual que en la narrativa anterior se busca proponer que las víctimas no poseen las competencias suficientes para vivir dentro de la ciudad; para este caso particular, lo que se propone no es establecer un proceso de adaptación para que las víctimas permanezcan en las ciudades, sino llevar los valores y axiologías de los núcleos urbanos a las comunidades. Los ejes conceptuales implicados con el ser, incluye la representación del ser humano usado por "otros"; el saber se articula a la competencia lingüística en la lengua dominante y, el hacer, incluye participación desarraigada de sus intereses en protestas callejeras u otras acciones que buscan restablecer derechos; se representa de esta manera falta de volición y agencialidad, responsabilizando a la comunidad embera-katío por la carencia de un conocimiento relacionado con la comprensión del español. Se elide así la responsabilidad del Estado para aplicar la política pública en educación etnolingüística en un país que cuenta con un capital simbólico que incluye su carácter multicultural, multiétnico y plurilingüe. En Colombia hay más de 102 pueblos aborígenes, grandes poblaciones afrocolombianas y la comunidad Rrom ${ }^{5}$. El plurilingüismo incluye más de sesenta idiomas o lenguas ancestrales, dos criollos de los pueblos afrocolombianos, el romaní, la lengua de señas y las múltiples variantes del español que se impone como la lengua oficial desde la organización de la nación (Ardila, 2009). Los factores de inadecuación social generan conflicto, con implicaciones socio-políticas, que conducen a que el Estado y sus instituciones asuman acciones que incluyen: diseño de evaluación social negativa de los miembros de la comunidad y, mediáticamente se construye la representación del temor entre los sectores implicados.

La representación mediática, además de indicar inadecuación social, al proponer a la comunidad como sujetos incapaces de participar activamente en el mercado lingüístico dominante, despoja a estas comunidades de sus potencialidades para la apropiación de decisiones y el gobierno local aplicando una política de remediación paternalista, donde se ejecuta el "regreso" como alternativa de solución. En este caso, se reitera el recurso de la objetualización al representar la comunidad como sujetos en uso, que pueden ser trasladados de un lugar a otro, ya sea por actores con rol político-administrativo o por agentes externos que desde el discurso dominante les promete "proveer orden"; "una condición de vida", o "una

5 “Comunidad Rrom" o "pueblo gitano" según las denominaciones del Ministerio de Cultura de Colombia. 
prebenda". "Hay líderes que los siguen invitando a irse a la ciudad y personas en Medellín que los sonsacan para que se vayan a ejercer la mendicidad y aprovecharse de ellos", denunció la alcaldesa Palomeque".

Lo que se puede indicar como el recurso más importante que aporta cohesión entre lo visual-gráfico y lo visual-lingüístico es la fragmentación discursiva que implica, por una parte, mostrar una representación determinada, y por otra, ocultar una determinada información que no permite enmarcar el problema de manera adecuada. En la relación entre conocer y desconocer, se produce "la puesta en escena comunicativa de conocimientos parciales" (Pardo Abril, 2007, p. 141) que jerarquiza los acontecimientos mostrados para cumplir con unos intereses y propósitos, que en esta narrativa corresponden a los de la institucionalidad. Siguiendo lo planteado por Martinec (2013), se produce una relación de elaboración donde el discurso escrito permite contextualizar la imagen, haciendo referencia a las condiciones de retorno de la comunidad indígena a su lugar ancestral.

\subsection{Deshumanización del sujeto social}

En el caso de los cuatro storytelling trabajados, se construyen representaciones sobre la víctima que tienen como propósito no solamente contextualizar sobre las acciones pasadas de los sujetos, sino también sugerir potenciales acciones en torno a una pretensión de control sobre el que es considerado como otro, y más específicamente, como amenaza. El Tiempo.com composicionalmente encuadra las imágenes y los titulares para crear una estigmatización que despoja a las personas de su humanidad, negándolos como semejantes y en el cuerpo de la narrativa utilizan recursos como la proscripción, en la cual se acusa al otro de infractor de normas sociales, para crear el sentido de peligro (Segovia y Jáimez, 2018).

En el storytelling "Humanizar al enemigo, ¿acaso no es humano ya?" la interrogación retórica del título tiene como garantía argumentacional la idea de que hay alguien que cuestiona la humanidad de los excombatientes y el propósito es tratar de controvertir este punto de vista, sin embargo, en el desarrollo de esa idea el redactor de este storytelling, a través de la selección marcadores verbales y visuales, genera una ruptura conceptual que neutraliza esa contraargumentación y ayuda a reforzar el punto de vista que controvierte. En el antetitular "Ver al enemigo público hacer el papel del bueno genera desconfianza, pero ¿cómo preferimos verlo?", el uso de la frase nominal enemigo público ya representa una modalización que muestra que se comparte el punto de vista del otro como enemigo; esto se complementa con la frase verbal "genera desconfianza" con lo cual se reafirma que el otro aún puede constituir un potencial peligro. Estos sentidos se amplifican con la imagen que acompaña el titular y el antetitular. 




Ilustración 3. "Humanizar al enemigo, ¿acaso no es humano ya?" (ElTiempo.com, 30 de mayo de 2017).

En el plano más cercano se encuentra un elemento que icónicamente se asemeja a un fragmento de malla que funciona como límite del campo de fútbol, pero también un límite entre el fotógrafo y lo fotografiado. Debido al punto de vista de la foto, la malla constituye también una frontera con el espectador lo que crea dos procesos: la exclusión del otro como algo que se puede ver, pero con lo que no se debe interactuar -porque genera peligro-; y, se formula una distancia social suficiente para evitar crear el sentimiento de empatía, lo cual se refuerza con la frontalidad del plano que impide subjetivizar lo enfocado. Otro efecto es la despersonalización de uno de los individuos, ya que el fragmento de malla le cubre el rostro configurando un anonimato, además de la despotencialización de la identidad del sujeto. Ese efecto está dado por la malla que funciona como un punto de fuga a través del cual se construyen los vectores de la imagen, creando líneas paralelas -ver línea roja y azul-con el camino de tierra que se observa en la montaña y que atraviesa la humanidad de los personajes representados.

El cuerpo de la narrativa primordialmente cumple dos funciones: contextualizar la situación de las zonas veredales en el municipio de Ituango en donde coexisten familias campesinas con excombatientes de las FARC; y contar el relato de Bladimir Aguilar, una las personas reintegradas siguiendo los criterios en concordancia con el Acuerdo de Paz, como forma de modelización de las maneras de ejercer ciudadanía en el postacuerdo.

El cuerpo de la narrativa se caracteriza primordialmente por la gestión de marcadores emocionales y citas de autoridad para construir una argumentación, cuyo propósito es el de formular a los excombatientes como humanos que también vivencian situaciones traumáticas y problemas cotidianos. Por un lado, los marcadores emocionales provienen principalmente de los estados psicológicos que el redactor de la narrativa como sujeto omnisciente le asigna al sujeto discursivo como en los siguientes casos: "Su temor es el rearme paramilitar en las zonas abandonadas por las Farc". "La desesperanza se apodera de él y sus compañeros cada vez que ven noticias que informan del asesinato de un guerrillero. Estos inconvenientes del proceso le han "bajado la nota a Bladimir". Por el otro lado, se citan referencias académicas como John Galtung o Boaventura da Souza Santos para generar una relativización del conflicto armado, que, sin embargo, por la forma en que se articulan a la línea argumentativa del periodista, terminan funcionando como maneras de trivialización y simplificación de la problemática social. "El sociólogo y matemático noruego, Johan Galtung, dice: "Todos los conflictos generan energía. El problema es cómo canalizarla constructivamente”, pero con las 
capacitaciones recibidas en la cárcel, donde aprendió a controlar sus emociones, Bladimir concentrará sus energías en su familia”. Lo que se genera en este fragmento discursivo es un ocultamiento de las causas estructurales por las cuales Bladimir y otros guerrilleros hicieron parte de este grupo armado, reduciéndolas a cuestiones de índole individual y psicológica como la falta de gestión de las emociones y las energías.

El resto del discurso sigue creando el sentido contrario al buscado inicialmente - la defensa de los excombatientes-, apelando a recursos como la justificación de actos de carácter atroz. En el fragmento "[...] la pobreza y la estigmatización a la que por siempre la ha tenido condenada y excluida el Estado [la zona], por ser acampadora de las guerrillas de las Farc" se asigna como causa de la exclusión generada por parte del Estado al hecho de que la zona alberga a las guerrillas de las Farc; en este caso, la personalización de la zona produce el ocultamiento de que la zona está sujeta a unas condiciones históricas por las que existe presencia de grupos armados ilegales y legitima cuestiones como la ausencia del Estado, la carencia de inversión pública y acceso a derechos como salud, educación, servicios públicos, vías y vivienda. Hablar de la zona como agente encubridor de un grupo guerrillero también formula un punto de vista que contribuye a reforzar los imaginarios negativos alrededor de las comunidades rurales del país. Esta representación del fenómeno se utiliza para elaborar una inferencia: a través del conector "por eso" se propone la implicatura de que por albergar a los grupos guerrilleros son merecedores de la acción criminal, justificando la acción de los paramilitares: “[...] en 1997 un comando paramilitar dejó sus casas convertidas en cenizas, tras no lograr asesinar a los hombres del pueblo".

Esto se complementa con la construcción de la amenaza que se encuentra a lo largo del texto, con recursos como nominación al usar las frases nominales "guerrilleros" y "enemigo público", lo cual formula una ontologización: la desmovilización no implica una transformación del estatus del sujeto, por lo cual se considera aún un peligro, socializando una forma de estigmatización que afecta la percepción de los interlocutores. En un fragmento específico del texto se formula una disquisición por el uso de vocativos para referirse a los excombatientes: Zulema, exintegrante del ELN señala que prefiere el uso del vocablo "victimario" en vez de "ofensor" por la carga semántica que conlleva, sin embargo, en otro fragmento del texto el periodista incide en el uso de la palabra "ofensores" como mecanismo de nominación lo cual omite la percepción identitaria que los mismos excombatientes formulan, desconociendo el punto de vista del actor discursiva y configurando un ejercicio abusivo por parte del periodista.

En esta misma narrativa aparece otra imagen donde se presenta deshumanización: se utiliza el recurso del plano medio recortando la parte superior del cuerpo humano, produciendo el mismo sentido de ocultamiento y de elisión de la identidad. Al igual que en la imagen anterior, también se utiliza un plano frontal para objetivar la situación de las personas representadas. Lo identitario únicamente se formula a través de la vestimenta y las cajas que portan algunos niños en la mano; en este caso, se activa el marco de la condición de pobreza. Los pobres al igual que los excombatientes, tradicionalmente han sido identificados desde la representación mediática como posibles amenazas. Esta estigmatización es reforzada por el entorno que es representado alrededor de los niños que está constituido por un suelo árido y por un terreno irregular y por un animal de corral que aparece en el plano más 
inmediato; la gallina es un símbolo que en la cultura occidental y colombiana está asociado con la precariedad. Aunque se pueda establecer que hay un ejercicio ético al no mostrar los rostros, se produce un fenómeno de espectacularización que implica encuadrar la imagen de manera que se produce una hipérbole de la situación de los actores representados generando una amplificación de lo construido en el discurso escrito. La línea roja marca el límite entre lo que está en primer plano y lo que está en segundo y los círculos rojos muestran que no hay un foco único en la imagen.

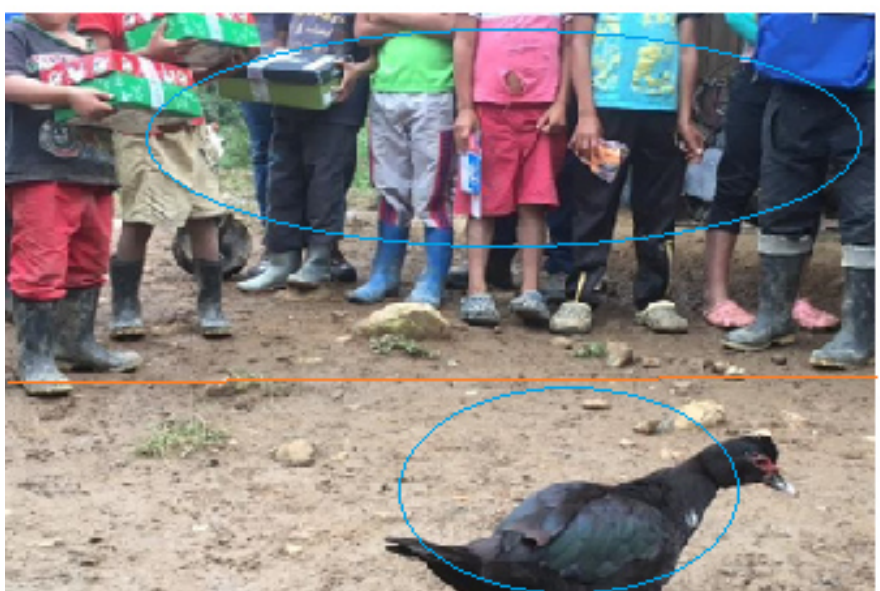

Ilustración 4. "Humanizar al enemigo, ¿acaso no es humano ya?" (ElTiempo.com, 30 de mayo de 2017).

\subsection{Desubjetivación del individuo}

Otra narrativa mediática que reproduce el mismo fenómeno de deshumanización es "Antes de ser guerrillero de las Farc fue víctima, ahora es líder" donde si bien el contenido de la narrativa es desarrollado por un excombatiente, lo que se propone es desestructurado por la selección del titular y la imagen que es realizada por el medio. Se construye un sentido negativo sobre la persona por su condición de excombatiente, con la diferencia de que en este caso se trata de matizar esto presentando las otras reflexividades del sujeto como víctima y como líder, y en el caso del antetitular como indígena. La imagen, sin embargo, despotencializa todas esas subjetividades.



Ilustración 5. “Antes de ser guerrillero de las Farc fue víctima, ahora es líder" (ElTiempo.com, 31 de mayo de 2017). 
La imagen se construye a través de un plano medio, que a diferencia del plano medio normal recorta la parte superior de la persona, lo que incluye el rostro que es la forma de acceso principal a los rasgos identitarios. Con el resto de los elementos indiciales como las botas -en general, la vestimenta- no es posible determinar si el sujeto representado es la misma persona que produce el testimonio. Por la forma de la presentación de la imagen, lo que se puede inferir es que se elide de la identidad de quien aparece en la fotografía la condición de guerrillero -y de víctima- ya que la persona se sitúa en el plano de lo dado, y no en el plano de lo remático que correspondería a la condición de líder. Como se sugiere en el análisis de esta imagen, no solamente son los excombatientes los que son deshumanizados sino también las víctimas como si víctima y victimario formaran parte del mismo conjunto social que debe ser motivo de estigma. La línea azul determina la orientación de los vectores de la imagen y la línea rojo la separación entre la información dada y la nueva.

En Colombia, debido a la coyuntura del conflicto, se configura una categoría social particular: víctima-victimario. El fenómeno es producido principalmente por el reclutamiento forzado de niños, niñas y jóvenes a las filas de los grupos armados, especialmente de zonas rurales. Sus actividades están principalmente vinculadas a "manejo y transporte de minas y explosivos, labores de inteligencia, logística y transporte de minas y víveres y alimentos" (Amador, 2010, p. 166). En estos casos, las experiencias incluyen eventos traumáticos, lo cual se produce una complejización del proceso de subjetivación; este es determinado en cierta medida por las condiciones sociales e históricas, pero también por el proceso individual que incluye la movilización de diferentes reflexividades, las cuales orientan las percepciones del mundo, creencias y acciones del individuo. Estas configuraciones de la subjetividad pueden poner en tensión regímenes de saber y poder y lógicas que son diversas y contradictorias, y que articulan distintos planos temporales y espaciales (Amador, 2010). En la narrativa analizada se presenta una intersección de planos institucionales e individuales ya que se da una combinación de voces y de representaciones entre el medio y la víctima-victimario que genera un nuevo discurso con un efecto de sentido diferente nuevo.

En la narrativa, el fenómeno socio-discursivo que la articula es la desubjetivación que está anclada al desprendimiento de sí del individuo (Foucault, 1999). Si bien la desubjetivación es inmanente a los procesos de construcción de la identidad, permitiendo su reconstrucción hacia una "pluralidad de posiciones y una discontinuidad de funciones" (Blanchot, 2009, p. 89), a partir de la orquestación semiótico-discursiva es posible producir una disolución e invisibilización del sujeto como ocurre con la imagen y también con la articulación entre esta y el discurso escrito que desancla la perspectiva del sujeto e introduce la del medio, lo cual se evidencia en la composición y repercute en la coherencia discursiva. "Antes de ser guerrillero de las Farc fue víctima, ahora es líder" es el relato del indígena Alejandro García que articula su perspectiva de pasado, presente y futuro, lo cual implica el planteamiento de una contextualización de los eventos vividos y presentes con el fin de generar discursivamente un futuro articulado al deseo. En ese sentido, siguiendo la teoría de la jerarquización de la información, la focalización se centra en el elemento remático, por lo que, siguiendo el titular y la organización argumentativa, lo fundamental es construir la imagen de Alejandro García como líder hacia el futuro, dejando en un segundo plano todas las demás reflexividades. 
Las identidades que se colocan en juego son, en primer lugar, la de Alejandro García como niño, centrando el foco en las actividades cotidianas y los sentimientos percibidos como protagonista de su propia narrativa:

En esa época vivíamos en la selva. Como indígena, una de nuestras costumbres es cultivar especialmente maíz, chontaduros, plátano y caña. Tenía 5 años, era muy feliz y vivíamos tranquilos, la montaña estaba en paz, así fueron pasando mis años, así pasaron los días (ElTiempo.com, 31 de mayo de 2017).

Se configura una primera espacio-temporalidad (selva-niñez) que da cuenta de la vida no solo del sujeto mismo sino de la vida de las comunidades indígenas donde se evidencia una conexión con la tierra y con la naturaleza, la cual no es ponderada positivamente en la sociedad capitalista de la producción y la acumulación. Aparte de los marcadores temporales- espaciales, se encuentran marcadores de identidad como "indigena", que refiere a la condición étnica, y los nominales "maíz", "chontaduros", "plátano" y "caña", que dan cuenta de la costumbre de sembrar comida para el autosostenimiento; y marcadores emocionales como "feliz", "tranquilos" y "paz", que no solo dan cuenta de la condición psicológica del personaje sino de las axiologías de la cultura ancestral propias del entorno donde nació y creció.

En segundo lugar, se habla de la intervención de la guerrilla dentro de la población donde pasó a vivir durante su época de juventud caracterizada por las constantes incursiones de los grupos armados. Alejandro García reivindica sus valores familiares y las acciones de sus padres, que le permitieron no entrar por voluntad propia a la guerrilla.

El líder le propuso a mi madre que trajera a sus hijos estudiar en la comunidad, pues los niños podían contar con alimentación y otras cosas que un estudiante necesita, como cuadernos, lápices y otros útiles escolares. Mis padres nos matricularon y así nos mantuvimos alejados por un tiempo de los grupos armados (ElTiempo.com, 31 de mayo de 2017).

En estos fragmentos discursivos se destaca la escuela como institución relevante para la socialización, como lugar donde se dan ciertas condiciones materiales necesarias para el desarrollo individual y como núcleo para evitar la entrada a los grupos armados. Sin embargo, a continuación, se menciona que la acción de la Fuerza Pública y las Farc aumentó la violencia armada y la guerrilla lo reclutó en contra de su voluntad, durando cinco años con ellos, incomunicado con sus seres cercanos y bajo unas lógicas de guerrerismo y muerte:

Pasaron cinco años y pude seguir con vida en las Farc, pues de varios nunca supe de su suerte, porque uno allá no puede preguntar si los demás están bien, pero se sabía que los habían matado por insubordinación o porque cayeron en combate. Estaba muy preocupado por esto y también cansado de tanto caminar y aguantar hambre en la montaña. Quería salir de allá, pero tenía miedo que me agarraran y me mataran (ElTiempo.com, 31 de mayo de 2017).

En este fragmento se involucra en el relato el entorno social de la guerrilla donde se observa una transformación de las lógicas e ideologías, con las que, sin embargo, el personaje no se identifica y sobre las que expresa una distancia social. Hasta este momento se produce la emergencia de una narrativa silenciada y una memoria privada, que se vuelve de carácter público, con la finalidad de evidenciar fenómenos propios del conflicto como la infiltración de los grupos armados legales 
e ilegales en las comunidades, las tácticas de guerra como el reclutamiento de niños o la diferencia entre el entorno natural de las comunidades en contraste con la vida dentro de la guerrilla. Para el año 2017, el Observatorio de Memoria y Conflicto da cuenta de aproximadamente 17 mil registros sobre el reclutamiento y utilización de niños, niñas y adolescentes para funciones no solo de combate sino también de apoyo logístico ya sea en tareas como los servicios de salud como de radio operación o patrullaje (CNMH, 2017).

A partir de este momento, el tenor del discurso cambia especialmente por la aparición del elemento institucional que entra en juego en la constitución del sujeto. En el siguiente fragmento, se habla sobre las entidades oficiales sobre las cuales se expresa una posición positiva:

En ese momento, había enfrentamientos con los demás guerrilleros, uno de ellos murió. Cuando todo se calmó, el comandante del Ejército se acercó y me preguntó cómo estaba, después me dijo: 'Te vamos a llevar con nosotros y recibirás apoyo por parte del Gobierno Nacional'. A pesar de todo, yo me sentía tranquilo con ellos (ElTiempo.com, 31 de mayo de 2017).

Además del Ejército, se hace hincapié en la labor del Instituto Colombiano de Bienestar Familiar -ICBF-y la Agencia Colombiana para la Reintegración como agentes positivos para la incorporación a la vida social y la posibilidad de retomar las actividades en su comunidad -awá-. El discurso termina acuñando valores de carácter hegemónico que refuerzan valores como el emprendimiento y la productividad, además de adoptar la perspectiva y la ideología del medio, ya que por el mismo fue posible tener una beca para poder aprender de storytelling y realizar esta narrativa:

Doy gracias a la Agencia Colombiana para la Reintegración y también a la Casa Editorial El Tiempo. Mi vida ha sido un proceso de aprendizaje, que retroalimenta cómo estamos viviendo en Colombia. Este proceso es una oportunidad inmensa en mi vida, me lleva a ser una persona emprendedora en la sociedad. Hoy soy una persona productiva. Para mí, este proceso lleva a construir cultura al pueblo awá y permite que los jóvenes no tomen el camino equivocado (ElTiempo.com, 31 de mayo de 2017).

Lo que se termina produciendo es una ruptura de la coherencia del texto: aunque da cuenta de la identidad del sujeto de manera explícita -ya que el mismo es el que la produce-, el dinamismo comunicativo produce un desplazamiento del sentido que termina haciendo que la voz y la subjetividad del sujeto termine permeada por visiones y representaciones de institucionales oficiales y se haga foco principalmente en los valores del medio. Siguiendo lo planteado por Martinec y Salway (2005), la imagen estaría subordinada al discurso escrito, en una relación de expansión, donde el texto elabora el propósito de la imagen de desubjetivizar al sujeto para imponer la lógica globalizada como condición para participar de manera restringida de la institucional que, como se ve en el título, se orienta hacia la noción de liderazgo, que en la sociedad colombiana se liga a los valores neoliberales y cuyo centro está en el crecimiento individual y no en la reconstrucción del tejido social.

\section{Conclusión}

El abordaje de las cuatro narrativas seleccionadas permite la deconstrucción de la representación que hace 'ElTiempo.com' de los sujetos victimizados, en el cual se producen modelos idealizados de comportamiento de víctimas que pasan por 
lugares como la adaptación a los núcleos urbanos y la adopción de valores hegemónicos, incluyendo la aceptación de formas de vestir y de actuar ancladas a las posiciones neoliberales y capitalistas. A pesar de que cada narrativa formula distintos tipos de construcción socio-discursiva, hay un vínculo común que es la producción del sentido de inadecuación social que está dado por la cohesión y coherencia de los storytelling, la cual es posible por las relaciones semánticopragmáticas entre discurso verbal y el discurso visual. La inadecuación se formula discursivamente alrededor de grupos que históricamente han sido subalternizados: LGTBI, las comunidades indígenas y negras, entre otras, ya sea en el rol de víctima como en las dos primeras narrativas; o como victimario y victimario-víctima correspondientemente- en los otros dos storytelling.

En "LGTBI, las víctimas que ya no quieren ser invisibles" la exclusión sociodiscursiva se elabora desde la idea de que los miembros de esta comunidad son víctimas por causa propia y se propone la inferencia que la decisión de desplazarse se da por su voluntad y no por una serie de condicionamientos sociales, donde no solo hay estigmatización por parte de las instituciones oficiales sino también de los grupos armados ilegales. Para lograr este efecto de sentido, se despliega principalmente la estrategia de legitimación que se construye a través de recursos como la modalización, por medio de la cual se supone el estado del actor discursivo, y por tanto, se opina sobre su manera de ser y actuar; la metaforización que objetualiza al sujeto victimizado y personifica a las regiones; y la autorización que utiliza la voz de delegados de entidades oficiales para contextualizar la situación de las víctimas LGTBI.

En lo referente a "Los embera-katío vuelven a su tierra ancestral", lo que se produce es una recontextualización donde se responsabiliza a los indígenas por las situaciones negativas vividas durante su desplazamiento a la ciudad, principalmente por su falta de adecuación social a situaciones propias de los contextos urbanos, ligadas no solo a las formas de actuar sino a la identidad que está atravesada por aspectos como la lengua. Para el ejercicio de esa recontextualización se utilizan recursos similares a los que aparecen en la primera narrativa, añadiendo otros como la cuantificación. En el caso de este storytelling se establece una complementariedad entre lo verbal y lo visual, ya que lo primero aporta información que permite la interpretación de lo segundo.

En "Humanizar al enemigo, ¿acaso no es humano ya?", el propósito expreso de apoyar discursivamente a los victimarios, mostrando una perspectiva humana de su situación pasada y actual, termina generando un ejercicio narrativo que logra el propósito comunicativo contrario: se despotencializa su subjetividad tanto en la imagen como en el discurso verbal y se formula la idea de que son sujetos inadecuados ontológicamente, sin importar su condición personal actual o las causas históricas por las cuales se ha producido su participación en el conflicto armado. Las interrogaciones retóricas, los marcadores emocionales y las formas de nominalización son algunos de los recursos empleados para justificar a los excombatientes como un peligro aún vigente del cual es necesario guardar una distancia social, como se observa en la imagen de la narrativa.

Dentro de la narrativa "Antes de ser guerrillero de las Farc fue víctima, ahora es líder" se repite la desubjetivación del actor social que ocurre en la anterior narrativa, para lo cual se usan algunos recursos similares como recortar al sujeto discursivo por la mitad sin mostrar la parte superior del cuerpo -ocultando así rasgos identitarios y de agencialidad del individuo-; y otros, como la alteración del tenor 
de la narrativa, que produce el cambio de la emergencia de una memoria subterránea como recurso de resistencia, a la adopción de la institucionalidad y de valores hegemónicos como mecanismo de adecuación social. En este storytelling, el propósito comunicativo se reconoce a través de la articulación de los modos semióticos, en la cual funcionalizada la voz del victimario-víctima a la visión e ideología del medio de comunicación.

El análisis de los storytelling permite verificar fenómenos que no contribuyen a la construcción del tejido social, sino que activan marcos colectivos que tienen la finalidad de mantener formas de marginalización, por una parte, a personas o grupos sociales que expresan planteamientos alternativos a los de la hegemonía, y, por otra parte, a quienes han experienciado, voluntaria o forzadamente el conflicto armado colombiano desde diferentes posiciones. Se hace necesario deconstruir este tipo de representaciones, para dar cuenta de sus consecuencias dentro de la coyuntura actual en Colombia, donde las narrativas y, en general, todas las expresiones que permiten construir memoria son fundamentales para la formulación de un futuro posible, donde haya condiciones de equidad, justicia, participación y, en general, donde haya garantías para la convivencia de todos los actores del conflicto armado con la ciudadanía en general.

\section{Referencias}

1. Alessandri, G., Vecchione, M., Eisenberg, N. y Łaguna, M. (2015). On the factor structure of the Rosenberg (1965) General Self-Esteem Scale. Psychological Assessment, 27, pp. 621-635. DOI: https://doi.org/10.1037/pas0000073

2. Agamben, G. (2011). ¿Qué es un dispositivo? Sociológica (México), 26(73), pp. 249-264.

3. Amador, J. C. (2010). El intersticio de la víctima-victimario: un análisis de los procesos de subjetivación de cuatro desvinculados de grupos armados en Colombia. Universitas humanística, 69, pp. 163-184.

4. Archila, M., García, M. C., Parra, L., y Restrepo, A. M. (2013). Luchas sociales en Colombia. Anuari del Conflicte Social, 3, pp. 553-611.

5. Ardila, $\bigcirc$. (2009). Lenguas indígenas y criollas de Colombia: un balance de su situación actual. Bogotá: Universidad Nacional de Colombia/Instituto Caro y Cuervo.

6. Bateman, J. A., Wildfeuer, J. y Hiippala, T. (2017). Multimodality: Foundations, Research and Analysis. A Problem-Oriented Introduction. Berlín: De Gruyter Mouton. DOI: https://doi.org/10.1515/9783110479898

7. Blanchot, M. (2009). Michel Foucault tal como lo imagino. Madrid: Arena Libros.

8. Busso, M. P., Gindin, I. L. y Schaufler, M. L. (2013). La identidad en el discurso. Reflexiones teóricas sobre investigaciones empíricas. La Trama de la Comunicación, 17, pp. 345-358.

9. Caballo, V. E., Piqueras, J. A., Antona, C., Irurtia, M. J., Salazar, I. C., Bas, P., y Salavera, C. (2018). La autoestima y su relación con la ansiedad social y las habilidades sociales. Psicología Conductual, 26(1), 23-53.

10. CINEP (2015). Alimentando el conflicto en Colombia: el impacto de 
la minería de oro en Chocó. Bogotá: Tierra Digna.

11. Centro Nacional de Memoria Histórica (CNMH, 2017). Informe de Gestión. Recuperado de:

http://centrodememoriahistorica.gov.co/descargas/transparencia/do cumentos-2017/informe-de-gestion-2017.pdf

12. Deleuze, G. (1990). Michel Foucault, filósofo. Barcelona: Gedisa.

13. ElTiempo.com (31 de mayo, 2017). LGTBI, las víctimas que ya no quieren ser invisibles. Recuperado de:

https://www.eltiempo.com/politica/proceso-de-paz/victimas-lgbtidel-conflicto-en-colombia-93848

14. ElTiempo.com (20 de mayo, 2017). Los embera katío vuelven a su tierra ancestral. Recuperado de:

https://www.eltiempo.com/politica/proceso-de-paz/los-emberakatio-vuelven-a-su-tierra-ancestral-89414

15. ElTiempo.com (30 de mayo, 2017). Humanizar al enemigo, ¿acaso no es humano ya? Recuperado de:

https://www.eltiempo.com/politica/proceso-de-paz/humanizar-alenemigo-acaso-no-es-humano-ya-91848

16. ElTiempo.com (31 de mayo, 2017). Antes de ser guerrillero de las Farc fue víctima, ahora es líder. Recuperado de:

https://www.eltiempo.com/politica/proceso-de-paz/testimonio-dealejandro-garcia-sobre-la-reintegracion-a-la-vida-civil-92104.

17. Fornero, A. y Artaza C. (2018). ¿Infantilización o feminización indígena? Reflexiones conceptuales para pensar el mestizaje. En: Cruz, G. R. (Coord.), Sujetos politicos indigenas. Indigenismos, mestizaje y colonialismo (pp. 99-118). Buenos Aires: Teseo Press.

18. Foucault, M. (1999b). Estética, ética y hermenéutica. Barcelona: Paidós.

19. Kress, G. y Van Leeuwen, T. (1996). Reading images: The grammar of visual design. Londres: Routledge.

20. Lakoff, G., y Johnson, M. (1986). Metáforas de la vida cotidiana. Madrid: Teorema.

21. Ledin, P., y Machin, D. (2018). Doing critical discourse studies with multimodality: from metafunctions to materiality. Critical Discourse Studies, 16(5), pp. 497-513. DOI:

https://doi.org/10.1080/17405904.2018.1468789

22. Leipold, S., y Winkel, G. (2017). Discursive Agency: (Re-

)Conceptualizing Actors and Practices in the Analysis of Discursive Policymaking. Policy Studies Journal, 45(3), pp. 510-534. DOI:

https://doi.org/10.1111/psj.12172

23. López-López, W., Sabucedo-Cameselle, J. M., Barreto, I., Borja, H., y Serrano, Y. (2014). Discourse as a Strategy for the Construction of Peace Cultures. En Sacipa-Rodriguez, S. y Montero, Maritza:

Psychosocial approaches to peace-building in Colombia (pp. 111120). Springer International Publishing: Cham. DOI:

https://doi.org/10.1007/978-3-319-04549-8_8

24. Martinec, R. (2013). Nascent and mature uses of a semiotic system: the case of image-text relations. Visual Communication, 12(2), pp. 147-172. https://doi.org/10.1177/1470357212471603

25. Martinec, R., y Salway, A. (2005). A system for image-text relations in 
new (and old) media. Visual Communication, 4(3), pp. 337-371. DOI: https://doi.org/10.1177/1470357205055928

26. Muro, M. y Jeffrey, P. (2008). A critical review of the theory and application of social learning in participatory natural resource management processes. Journal of environmental planning and management, 51(3), pp. 325-344. DOI: https://doi.org/10.1080/09640560801977190

27. Olave, G. (2014). Aproximaciones retóricas al conflicto armado colombiano: una revisión bibliográfica. Forma y Función, 27(1), pp. 155-197. DOI: https://doi.org/10.15446/fyf.v27n1.46951

28. Pardo Abril, Neyla (2007). ¿Cómo hacer análisis crítico del discurso? Una perspectiva latinoamericana. Santiago de Chile: Frasis.

29. Pardo Abril, Neyla (2014). Discurso en la web: pobreza en Youtube. Bogotá: UNAL-IECO.

30. Pardo Abril, Neyla (2016). De los Estudios Críticos del Discurso a los Estudios Críticos de los Discursos multimodales. En Pardo Abril, N. y Forero, C. (Eds.), Introducción a los Estudios Críticos del Discurso Multimodal. Bogotá: UNAL-IECO. DOI: https://doi.org/10.35956/v.8.n1.2008.p.77-107

31. Pardo Abril, Neyla (2017). Aproximación al despojo en Colombia. Bogotá: Universidad Nacional de Colombia.

32. Pardo Abril, Neyla (2020). Memorialización y conflicto armado: la construcción de narrativas para la paz en Colombia. Rev. Estud. Ling., Belo Horizonte, 28(1), pp. 479-506. DOI:

https://doi.org/10.17851/2237-2083.28.1.479-506

33. Rumelili, B. (2013). Identity and desecuritisation: the pitfalls of conflating ontological and physical security. Journal of International Relations and Development, 18(1), pp. 52-74. DOI: https://doi.org/10.1057/jird.2013.22

34. Segovia, A., y Jáimez, R. (2018). ¿Adversario o enemigo? La expresión discursiva de la violencia hacia el otro en el discurso de Hugo Chávez Frías. Una aproximación diacrónico-contextual. Discurso y Sociedad, 2, pp. 255-296.

35. Shrum, L. J. (2002). Media consumption and perceptions of social reality: Effects and underlying processes. En: J. Bryant and D. Zillmann (Eds.) Media Effects: Advances in Theory and Research (pp. 69-95). Mahwah, NJ: Lawrence Erlbaum Association.

36. Stoichita, V. (2005). La tematización de la mirada en la pintura impresionista. Madrid: Ediciones Siruela.

37. Van Leeuwen, T. (2007). Legitimation in discourse and communication. Discourse \& Communication, 1(1), pp. 91-112. DOI: https://doi.org/10.1177/1750481307071986 